Iğdır Üniversitesi Fen Bilimleri Enstitüsü Dergisi, 11(2): 1050-1057, 2021

Journal of the Institute of Science and Technology, 11(2): 1050-1057, 2021

ISSN: 2146-0574, eISSN: 2536-4618

Fizik / Physics

DOI: $10.21597 /$ jist.858524

Araştırma Makalesi / Research Article

Received: 11-01-2021

Accepted: 03-02-2021

To Cite: Yilmaz M, 2021. Electrical Characterization of CdO Based Au/p-Si Rectifier. Journal of the Institute of Science and Technology, 11(2): 1050-1057.

\title{
Electrical Characterization of CdO Based Au/p-Si Rectifier
}

\section{Mehmet YILMAZ1*}

\begin{abstract}
Cadmium oxide (CdO) film was developed using a chemical spray pyrolysis technique on the p-type silicon ( $\mathrm{p}-\mathrm{Si}$ ) substrate. The solution of the $\mathrm{CdO}$ was obtained by dissolving cadmium acetate salt in a mixture of distilled water and methanol. High-quality $\mathrm{Au}$ and $\mathrm{Al}$ contacts were evaporated on the polished and unpolished side of $\mathrm{p}-\mathrm{Si}$, respectively to create $4 \mathrm{Au} / \mathrm{CdO} / \mathrm{p}-\mathrm{Si} / \mathrm{Al}$ device architecture. In this context, four $\mathrm{Au} / \mathrm{CdO} / \mathrm{p}-\mathrm{Si} / \mathrm{Al}$ devices that were arbitrarily favored were analyzed and compared in depth. Current-Voltage (I-V) measurements were carried out to find out the performance of the $\mathrm{CdO}$ interlayer in the $\mathrm{Au} / \mathrm{p}$-Si device. The obtained data were analyzed using the Thermionic emission theory, Norde, and Cheung approach. Results indicated that $\mathrm{CdO}$ films grown by simple chemical spray pyrolysis technique could be used as barrier modifiers in Au/p-Si rectifier device.
\end{abstract}

Keywords: CdO, Spray pyrolysis, Schottky Junction, rectifier

${ }^{1}$ Mehmet YILMAZ (Orcid ID: 0000-0002-4368-8453), Atatürk University, K.K Education Faculty, Department of Science Teaching, Erzurum, Turkey

*Corresponding Author: Mehmet YILMAZ, e-mail: yilmazmehmet32@gmail.com 


\section{INTRODUCTION}

In recent years, TCO films (such as ITO and $\mathrm{SnO}_{2}$ ) have gained attention due to their low resistance and high transparency (Ferro, 1999). Besides, indium's recently included as critical raw material and it's being very expensive has forced researchers to work on materials alternative to ITO (Ylä-Mella et al., 2016). At this stage, the electrical resistance of the $\mathrm{CdO}$ film is between $10^{-2}-10^{-4}$ $\Omega . \mathrm{cm}$, and the optical band gap between 2.2 and $2.7 \mathrm{eV}$. These behaviors highlight the potential of CdO to be used as an alternative to ITO in device applications. Moreover, native defects such as oxygen vacancies and cadmium interstitials are responsible for the electrical conduction of pure $\mathrm{CdO}$. Controllable of conductivity and optical properties of $\mathrm{CdO}$ films by controlling natural defects makes $\mathrm{CdO}$ films interesting in hetero-junction applications. Although these properties can be adjusted for the desired application with external effects such as doping, they can also be changed depending on the experimental method (Sankarasubramanian et al., 2015). In this context, depending on the growth method, the natural defect rates that affect the characteristics of $\mathrm{CdO}$ films can be changed by controlling some process parameters such as the concentration of the solution, the temperature of the substrate and the solution flow rate, the pressure of the growth condition (Gupta et al., 2008; Murthy et al., 1999).

According to the literature, the $\mathrm{CdO}$ films are obtained with many growth methods. Among them, pulsed laser deposition (Menazea et al., 2020), radiofrequency magnetron sputtering (Saha et al., 2008), metalorganic chemical vapor deposition (MOCVD) (Jin et al., 2004) are frequently used to obtain highquality $\mathrm{CdO}$ films, which are suitable for many applications. However, these techniques require a lot of time to reach the desirable vacuum rate as well as being expensive can be thought the disadvantages of these techniques (Wang et al., 2018). Recently, the spray pyrolysis technique provides an easy way to obtain high-quality metal oxide-based thin films (Khodair et al., 2020; Mahesh et al., 2020). The chemical spray pyrolysis technique (CST), one of the important production methods, provides one-stage production and homogeneous particle composition. In CST, the primary preparation conditions affecting film properties are precursors and solvents (Afify et al., 2014). Therefore, it is important to investigate the performance of $\mathrm{CdO}$ films obtained by CST in device applications in order to reveal the performance of the CST.

This article examines the performance of the CdO thin film made by the solution-based CST in $\mathrm{Au} / \mathrm{p}-\mathrm{Si}$ device as an alternative to the $\mathrm{CdO}$ films growth by vacuum-requiring growth methods mentioned above. The obtained $\mathrm{Au} / \mathrm{CdO} / \mathrm{p}-\mathrm{Si} / \mathrm{Al}$ was characterized by current-voltage $(\mathrm{I}-\mathrm{V})$ analyses at room temperature.

\section{MATERIALS AND METHODS}

To obtain better performance, the p-Si wafer was firstly cleaned up by a cleaning procedure called the RCA (Kern, 1990). The Al contact $(100 \mathrm{~nm})$ was then vaporized to the unpolished side of the p-Si and thermally annealed at $500{ }^{\circ} \mathrm{C}$ for 5 minutes for ohmic contact. A simple experimental setup was used to perform the deposition of $\mathrm{CdO}$ thin films by the CST. As source material, the cadmium acetate $\left(\mathrm{Cd}\left(\mathrm{CH}_{3} \mathrm{COO}\right)_{2} \cdot 2 \mathrm{H}_{2} \mathrm{O}\right)$ was preferred and it was dissolved in a mixture of deionized water and methanol (volumetric ratio of deionized water/methanol was adjusted as 1: 1). The final solution was sprayed onto the $\mathrm{p}$-Si substrate at a flow rate of $2 \mathrm{~mL} / \mathrm{min}$ at $250^{\circ} \mathrm{C}$ substrate temperature. The properties of the $\mathrm{p}$-Si substrate were given in our previous publications (Turgut et al., 2021),. Finally, Au dot contacts were evaporated by thermal evaporation onto the $\mathrm{CdO}$ films to create $\mathrm{Au} / \mathrm{CdO} / \mathrm{p}-\mathrm{Si} / \mathrm{Al}$ device architecture. Electrical evaluations were made by taking into account the current-voltage (I-V) measurements obtained using the KEITHLEY 487 Picoammeter/Voltage Source and the results were discussed in detail. 


\section{RESULTS AND DISCUSSION}

Semi-logarithmic I-V plots of the $\mathrm{Au} / \mathrm{p}-\mathrm{Si} / \mathrm{Al}$ (reference) and $\mathrm{Au} / \mathrm{CdO} / \mathrm{p}-\mathrm{Si} / \mathrm{Al}$ device points have been given in Fig.1. According to the semi-logarithmic I-V curves of the samples, the fabricated devices exhibited strong rectifying properties, but the rectifying properties changed from device to device. Variations in I-V graphs can be due to metallic contacts or measurement errors as well as non-uniform interface layers, as we noted in our previous publication (Kocyigit et al., 2019).

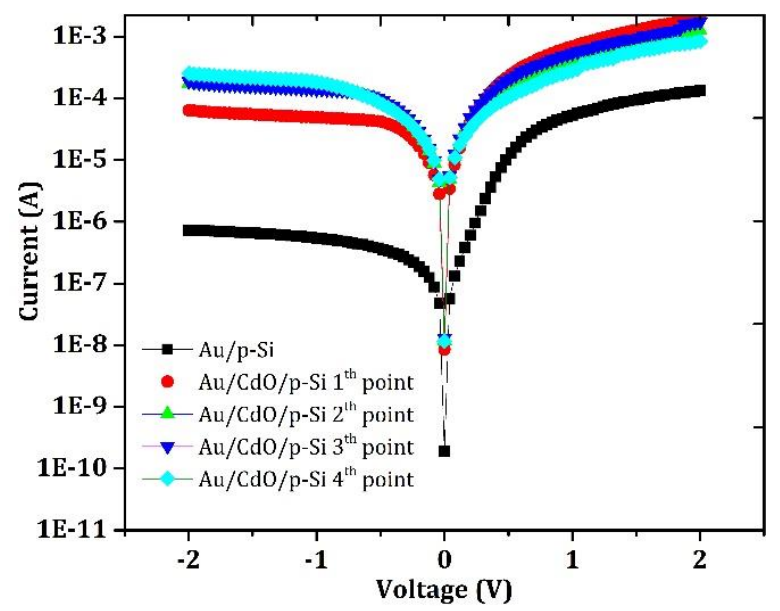

Fig.1. I-V plot of the various $\mathrm{Au} / \mathrm{p}-\mathrm{Si} / \mathrm{Al}$ and $\mathrm{Au} / \mathrm{CdO} / \mathrm{p}-\mathrm{Si} / \mathrm{Al}$ device points

We performed I-V analysis considering the thermionic emission theory to obtain detailed information regarding the influence of layer inhomogeneity on the properties of $\mathrm{Au} / \mathrm{CdO} / \mathrm{p}-\mathrm{Si} / \mathrm{Al}$ device. In the presence of the interfacial layer of $\mathrm{CdO}$, the correlations between current and voltage can be associated with Eq.(1), taking into account the thermionic emission (TE) principle (Karataş et al., 2003).

$I=I_{0}[\exp (q V / n k T)-1]$

where, $I_{0}$ is the current of saturation and given via the following formula:

$I_{0}=A A^{*} T^{2} \exp \left(-q \varphi_{b} / k T\right)$

Some of the notations seen in Eqs, (1-2) such as $q, T, \varphi_{b} V, k, A^{*}, R s, A$, and $n$ are electron charge, temperature, height of the zero bias barrier, applied voltage, Boltzmann constant, Richardson constant $\left(32 \mathrm{~A} /\left(\mathrm{cm}^{2} \cdot \mathrm{K}^{2}\right)\right.$ for $\left.\mathrm{p}-\mathrm{Si}\right)$, series resistance, diode area, and, ideality factor, respectively. If $V>3 \mathrm{kT} / \mathrm{q}$, the ideality factor may be organized from eq.(1) as below (Karataş et al., 2007):

$n=q / k T[d V / d(\ln I)]$

The meaning of the ideality factor " $n$ " is unity for the ideal device according to simple TE theory.

However, variation from the unity is inevitable because of certain factors such as the presence of the oxide layer between the materials of the junctions and the decrease in IRs caused by the effect of series resistance $\mathrm{R}_{\mathrm{S}}$ (Grilli et al., 2016). Also, this behavior is called a non-ideal diode feature. For the non-ideal diode, zero bias barrier height values can be calculated using Eq. (4):

$\varphi_{b}=\frac{k T}{q} \ln \left(A A^{*} T^{2} / I_{0}\right)$ 
Table 1 provides the measured barrier height values and ideality factor obtained from the standard I-V approximation for the $\mathrm{Au} / \mathrm{p}-\mathrm{Si} / \mathrm{Al}$ and $\mathrm{Au} / \mathrm{CdO} / \mathrm{p}-\mathrm{Si} / \mathrm{Al}$ device points.

Table 1. Comparing device points of $\mathrm{Au} / \mathrm{p}-\mathrm{Si} / \mathrm{Al}$ and $\mathrm{Au} / \mathrm{CdO} / \mathrm{p}-\mathrm{Si} / \mathrm{Al}$ 's characteristics

\begin{tabular}{cccccccc}
\hline \multirow{2}{*}{ Sample } & Saturation & \multirow{2}{*}{$n(\mathrm{TE})$} & $\varphi_{b}(\mathrm{eV})(\mathrm{TE})$ & \multicolumn{2}{c}{ Cheung } & \multicolumn{2}{c}{ Norde } \\
\cline { 5 - 8 } & Current $\left(I_{0}\right)$ & & & $n$ & $\varphi_{b}(\mathrm{eV})$ & $\varphi_{b}(\mathrm{eV})$ & $R_{s}(\mathrm{k} \Omega)$ \\
\hline Ref. & $7.80 \times 10^{-8}$ & 7.73 & 0.68 & 8.12 & 0.63 & 0.71 & 1.29 \\
$1^{\text {th }}$ point & $4.04 \times 10^{-8}$ & 1.52 & 0.70 & 3.86 & 0.56 & 0.61 & 1.48 \\
$2^{\text {th }}$ point & $5.19 \times 10^{-8}$ & 1.55 & 0.69 & 3.90 & 0.35 & 0.60 & 1.02 \\
$3^{\text {th }}$ point & $6.55 \times 10^{-8}$ & 1.54 & 0.69 & 4.02 & 0.54 & 0.60 & 0.93 \\
$4^{\text {th }}$ point & $4.38 \times 10^{-8}$ & 1.57 & 0.70 & 6.57 & 0.48 & 0.58 & 2.13 \\
\hline
\end{tabular}

According to Table 1, it is seen that the values of the ideality factor for different device points are larger than the unity. This situation demonstrates that, as stated before, the fabricated devices exhibit non-ideal diode behavior. Besides, it has been found that the ideality factor's value of the reference sample is very high. In the literature (Gupta et al., 2009a, 2009b), a higher ideality factor is seen for devices with different device architectures, especially in calculations using data in the high forward bias area. The high ideality factor may be attributed to many factors, such as the rapid recombination of electrons and holes in the area of depletion, interface state density effect, and the presence of imperfections between metal/semiconductor interlayer (Akinn et al., 2019; Yeganeh et al., 2010). Moreover, a considerable decrease in the ideality factor has been observed with the use of $\mathrm{CdO}$ as the interface material in the $\mathrm{Au} / \mathrm{p}-\mathrm{Si}$ device. This situation can be shown as evidence that $\mathrm{CdO}$ affects the barrier height of conventional $\mathrm{Au} / \mathrm{p}-\mathrm{Si}$ contacts. As for the $\mathrm{CdO} / \mathrm{p}-\mathrm{Si}$ contact, the silicon and $\mathrm{CdO}$ electron affinities are $4.05 \mathrm{eV}$ and $3.45 \mathrm{eV}$, respectively. Therefore, the Schottky barrier occurs at the $\mathrm{CdO} / \mathrm{p}-\mathrm{Si}$ junction (Bagal et al., 2016; Soylu et al., 2012). The values shown in Table 1 shows the correlation between the barrier height and the ideality factor. Hence, the barrier inhomogeneities can be seen with a slight difference with the change of diode points. The fact that all the $\varphi_{b}$ values are similar to each other indicates the barrier height's homogeneous nature. Thus, the small inconsistency in the $\mathrm{CdO}$ diodes' barrier heights is thought to be because of the difference in the carrier concentration of $\mathrm{CdO}$ in the studied area because of $\mathrm{CdO}$ film is not homogeneously distributed on the surface.

An alternative way of calculating the diode parameters like the barrier height value of these types of devices is the Norde method. The following equation can be applied to compute the barrier height of four $\mathrm{Au} / \mathrm{CdO} / \mathrm{p}-\mathrm{Si}$ devices (Lien et al., 1984):

$F(V)=\frac{V}{\gamma}-\frac{k T}{q} \ln \left[\frac{I(V)}{A A^{*} T^{2}}\right]$

where, $\gamma$ indicates an integer that should be higher than the $n$ defined by the TE, and the $\mathrm{I}(\mathrm{V})$ indicates bias based on current. The F (V)-V diagram of four Au/CdO/p-Si devices have been shown in Fig. 2 and Table 1 provides these curves' estimated parameters have been given. From the values shown in Table 1 , it can be concluded that the obtained values of $\varphi_{b}$ differ slightly from the values obtained from other methods. Series resistance is another significant parameter for similar devices. Therefore, calculating the series resistance is essential in determining the performance of such devices (Ocak et al., 2009). 


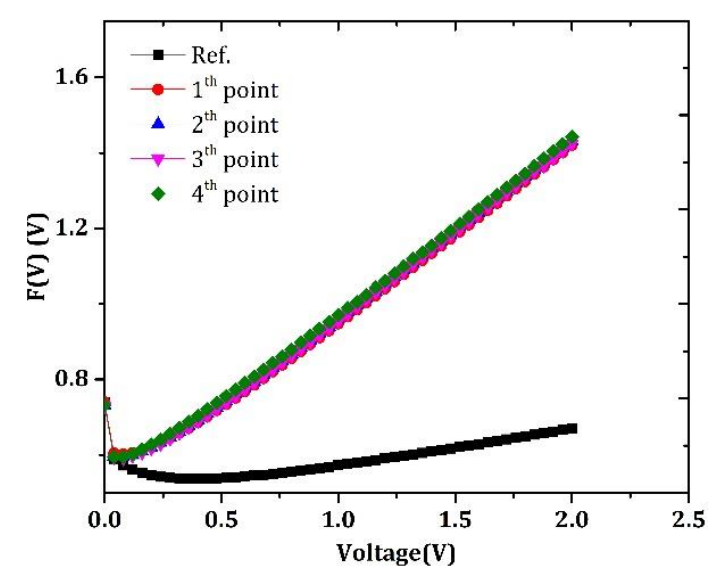

Fig.2. The Norde plot of the $\mathrm{Au} / \mathrm{p}-\mathrm{Si} / \mathrm{Al}$ and $\mathrm{Au} / \mathrm{CdO} / \mathrm{p}-\mathrm{Si} / \mathrm{Al}$ device points

$R_{S}=\frac{\gamma-n}{I}\left(\frac{k T}{q}\right)$

The calculated series resistance values are given in Table 1 , and values of $\mathrm{k}(\Omega)$ order have been obtained with the differences for each diode point. As mentioned earlier, the observed difference in both barrier height and series resistance values may be due to measurement errors as well as to the $\mathrm{CdO}$ interface growing inhomogeneously on the p-Si wafer.

According to Cheung method, the current expression of diode can be represented as follows depending on $R_{s}$ (Kocyigit et al., 2019; Singh et al., 2015).

$I=I_{0} \exp \left(-\frac{q\left(V-I R_{S}\right)}{n k T}\right)$

The $I R_{S}$ is the drop at voltage because of the series resistance. Hence, diode parameters such as ideality factor and barrier height can be obtained using Cheung approximations under the effect of series resistance. For this, the equations known as Cheung approximations can be used.

$\frac{d V}{d(\ln I)}=\frac{n k T}{q}+I R_{S}$

$H(I)=V-\left(\frac{n k T}{q}\right) \ln \left(\frac{I}{A A^{*} T^{2}}\right)$

$H(I)=n \varphi_{b}+I R_{S}$

By considering Eqs. (8-10), $d V / d \ln (I) v s .(I)$ and $H(I)$ vs.(I) curves can be drawn with a linear nature. In addition, some diode parameters such as series resistance, barrier height, and ideality factor are given by the slope and $\mathrm{y}$-axis intercept of these curves. The $d V / d \ln (I) v s$.(I) and $H(I) v s .(I)$ plots of the $\mathrm{Au} / \mathrm{p}-\mathrm{Si} / \mathrm{Al}$ and $\mathrm{Au} / \mathrm{CdO} / \mathrm{p}-\mathrm{Si} / \mathrm{Al}$ device points have been shown in Fig. 3 and calculated diode parameters have been listed in Table 1. From the values given in Table 1, it is seen that the $n$ and $\varphi_{b}$ values obtained by the Cheung approach are not in good agreement with those derived from values of thermionic emission theory. Non-ideal device configurations may be correlated with discrepancies between $\mathrm{n}$ and $\varphi_{b}$ values for the same device. (Yildirım, 2019). 

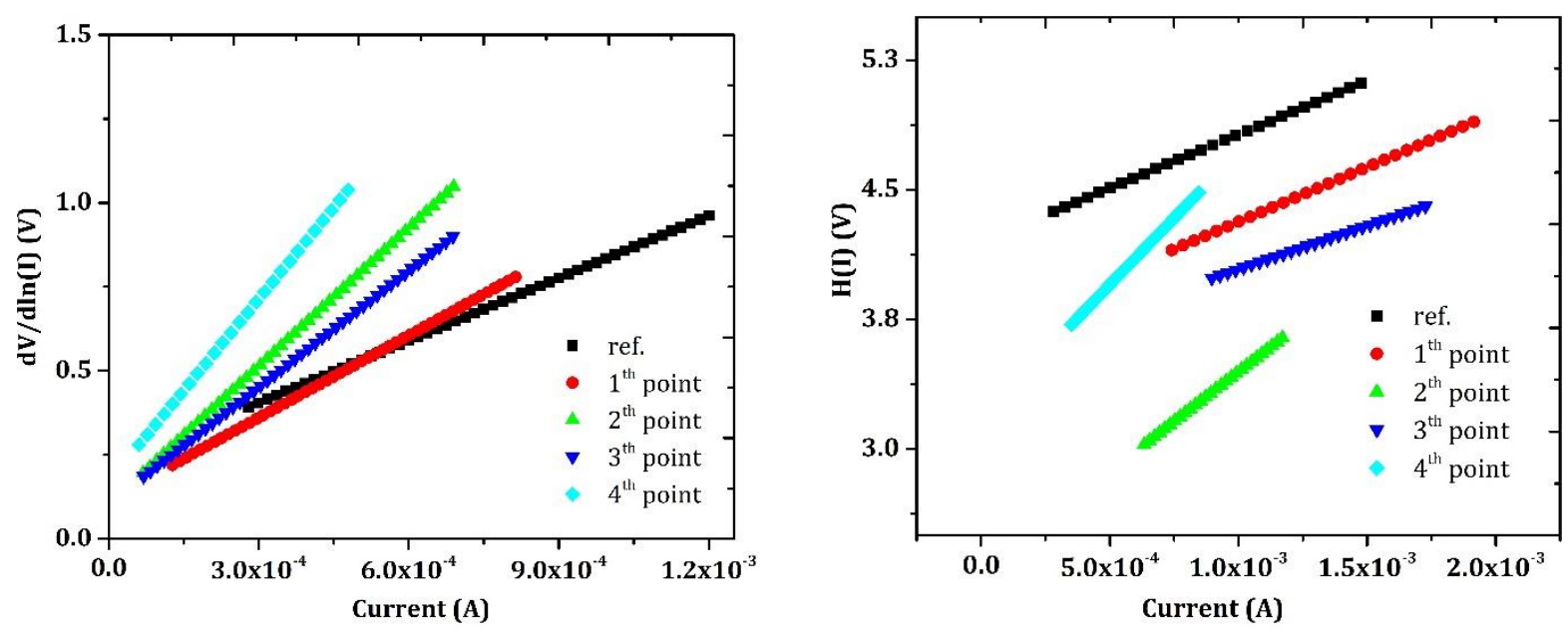

Fig.3. A plot of dV/dln(I) vs.(I) and $\mathrm{H}(\mathrm{I})$ vs.(I) of the $\mathrm{Au} / \mathrm{p}-\mathrm{Si} / \mathrm{Al}$ and $\mathrm{Au} / \mathrm{CdO} / \mathrm{p}-\mathrm{Si} / \mathrm{Al}$ device points

Actually, this difference can be explained by taking differences in calculations into consideration. While the TE approach uses the data of the I-V plot in the linear region to measure the diode parameters, the Cheung method uses the data in the nonlinear region of the I-V curves where the interface states and $R_{s}$ are efficient. Similar interpretations have been by other researchers to explain the differences between Norde, Cheung, and TE approximations (Sağlam et al., 2004; Tataroğlu et al., 2009; Yilmaz, 2019).

\section{CONCLUSION}

The CdO thin film was grown on the p-type Si by the CST. To examine the device performance of the $\mathrm{CdO}$ film in the $\mathrm{Au} / \mathrm{p}$-Si device, Au gold contacts were evaporated on the $\mathrm{CdO}$ film and the 4 $\mathrm{Au} / \mathrm{CdO} / \mathrm{p}-\mathrm{Si} / \mathrm{Al}$ device structure was completed. In this context, the device parameters of $4 \mathrm{Au} / \mathrm{CdO} / \mathrm{p}-$ $\mathrm{Si} / \mathrm{Al}$ devices were determined using different methods depending on $\mathrm{I}-\mathrm{V}$ analysis and compared in terms of various device point effects. Accordingly, while the ideality factor varied between 1.52-1.57, the barrier height varied between $0.70-0.69 \mathrm{eV}$, indicating the homogeneous nature of the barrier height. The small differences here were attributed to the difference in carrier concentration of $\mathrm{CdO}$ in the device being studied because the $\mathrm{CdO}$ film is not homogeneously distributed over the p-Si backing.

\section{ACKNOWLEDGEMENTS}

The author would like to thanks H.Kacus and A.Ozmen for their valuable contributions.

\section{Conflict of Interest} article.

I declare that there is no conflict of interest during the planning, execution and writing of the

\section{Author's Contiibutions}

I hereby declare that the planning, execution and writing of the article was done by me as the sole author of the article.

\section{REFERENCES}

Afify HH, Ahmed NM, Tadros MY, Ibrahim FM, 2014. Temperature dependence growth of CdO thin film prepared by spray pyrolysis. Journal of Electrical Systems and Information Technology, 1(2), pp:119-128. doi: 10.1016/j.jesit.2014.07.001

Akinn Ü, Yüksel ÖF, Pakma O, Koralay H, Cavdar S, Tugluoglu N, 2019. A Novel Device Behavior Of Al / Coronene / n-GaAs / In Organic Based Schottky Barrier Diode. New Materials, Compounds and Applications, pp:15-22. 
Bagal VS, Patil GP, Deore AB, Suryawanshi SR, Late DJ, More MA, Chavan PG, 2016. Surface modification of aligned $\mathrm{CdO}$ nanosheets and their enhanced field emission properties. RSC Advances, 6(47), pp:4126141267. doi: 10.1039/C5RA28000A

Ferro R, 1999. Some physical properties of F-doped CdO thin films deposited by spray pyrolysis. Thin Solid Films, 347(1-2), pp:295-298. doi: 10.1016/S0040-6090(99)00006-1

Grilli ML, Aydogan S, Yilmaz M, 2016. A study on non-stoichiometric p-NiOx/n-Si heterojunction diode fabricated by RF sputtering: Determination of diode parameters. Superlattices and Microstructures, 100, pp:924-933. doi: 10.1016/j.spmi.2016.10.059

Gupta RK, Ghosh K, Kahol, PK, 2009a. Fabrication and electrical characterization of Au/p-Si/STO/Au contact. Current Applied Physics, 9(5), pp:933-936. doi: 10.1016/j.cap.2008.09.007

Gupta RK, Ghosh K, Kahol PK, 2009b. Fabrication and electrical characterization of Schottky diode based on 2amino-4, 5-imidazoledicarbonitrile (AIDCN). Physica E: Low-Dimensional Systems and Nanostructures, 41(10), pp:1832-1834. doi: 10.1016/j.physe.2009.07.009

Gupta RK, Ghosh K, Patel R, Mishra SR, Kahol PK, 2008. Structural, optical and electrical properties of In doped $\mathrm{CdO}$ thin films for optoelectronic applications. Materials Letters, 62(19), pp:3373-3375. doi: 10.1016/j.matlet.2008.03.015

Jin S, Yang Y, Medvedeva JE, Ireland JR, Metz AW, Ni J, Kannewurf CR, Freeman AJ, Marks TJ, 2004. Dopant Ion Size and Electronic Structure Effects on Transparent Conducting Oxides. Sc-Doped CdO Thin Films Grown by MOCVD. Journal of the American Chemical Society, 126(42), pp:13787-13793. doi: 10.1021/ja0467925

Karataş Ş, Altındal Ş, Türüt A, Çakar, M, 2007. Electrical transport characteristics of Sn/p-Si schottky contacts revealed from I-V-T and C-V-T measurements. Physica B: Condensed Matter, 392(1-2), pp:43-50. doi: 10.1016/j.physb.2006.10.039

Karataş Ş, Altındal Ş, Türüt A, Özmen A, 2003. Temperature dependence of characteristic parameters of the Hterminated Sn/p-Si(1 0 0 $)$ S Schottky contacts. Applied Surface Science, 217(1-4), pp:250-260. doi: 10.1016/S0169-4332(03)00564-6

Kern W, 1990. The Evolution of Silicon Wafer Cleaning Technology. Journal of The Electrochemical Society, 137(6), pp:1887-1892. doi: 10.1149/1.2086825

Khodai ZT, Abdulmunem Ibrahim B, Kaream Hassan M, 2020. Investigation on the structural and optical properties of copper doped NiO nanostructures thin films. Materials Today: Proceedings, 20, pp:560-565. doi: 10.1016/j.matpr.2019.09.189

Kocyigit A, Yılmaz M, Aydoğan Ş, İncekara Ü, 2019. The effect of measurements and layer coating homogeneity of $\mathrm{AB}$ on the $\mathrm{Al} / \mathrm{AB} / \mathrm{p}-\mathrm{Si}$ devices. Journal of Alloys and Compounds, 790, pp:388-396. doi: 10.1016/j.jallcom.2019.03.179

Lien CD, So FCT, Nicolet MA, 1984. An improved forward I-V method for nonideal Schottky diodes with high series resistance. IEEE Transactions on Electron Devices, 31(10), pp:1502-1503. doi: 10.1109/TED.1984.21739

Mahesh D, Kumar MCS, 2020. Synergetic effects of aluminium and indium dopants in the physical properties of $\mathrm{ZnO}$ thin films via spray pyrolysis. Superlattices and Microstructures, 142, p:106511. doi: 10.1016/j.spmi.2020.106511

Menazea AA, Mostafa AM, Al-Ashkar EA, 2020. Impact of $\mathrm{CuO}$ doping on the properties of $\mathrm{CdO}$ thin films on the catalytic degradation by using pulsed-Laser deposition technique. Optical Materials, 100, p:109663. doi: 10.1016/j.optmat.2020.109663

Murthy LCS, Rao KSRK, 1999. Thickness dependent electrical properties of CdO thin films prepared by spray pyrolysis method. Bulletin of Materials Science, 22(6), pp:953-957. doi: 10.1007/BF02745685

Ocak YS, Kulakci M, Kılıçoğlu T, Turan R, Akkılıç K, 2009. Current-voltage and capacitance-voltage characteristics of a Sn/Methylene Blue/p-Si Schottky diode. Synthetic Metals, 159(15-16), pp:1603-1607. doi: 10.1016/j.synthmet.2009.04.024 
Sağlam M, Biber M, Çakar M, Türüt A, 2004. The effects of the ageing on the characteristic parameters of polyaniline/p-type Si/Al structure. Applied Surface Science, 230(1-4), pp:404-410. doi: 10.1016/j.apsusc.2004.03.003

Saha B, Thapa R, Chattopadhyay KK, 2008. Wide range tuning of electrical conductivity of RF sputtered CdO thin films through oxygen partial pressure variation. Solar Energy Materials and Solar Cells, 92(9), pp:10771080. doi: 10.1016/j.solmat.2008.03.024

Sankarasubramanian K, Soundarrajan P, Sethuraman K, Ramamurthi K, 2015. Chemical spray pyrolysis deposition of transparent and conducting Fe doped $\mathrm{CdO}$ thin films for ethanol sensor. Materials Science in Semiconductor Processing, 40, pp:879-884. doi: 10.1016/j.mssp.2015.07.090

Singh BK, Tripathi S, 2015. Fabrication and characterization of Au/p-ZnO Schottky contacts. Superlattices and Microstructures, 85, pp:697-706. doi: 10.1016/j.spmi.2015.06.038

Soylu M, Girtan M, Yakuphanoglu F, 2012. Properties of PEDOT:PEG/ZnO/p-Si heterojunction diode. Materials Science and Engineering: B, 177(11), pp:785-790. doi: 10.1016/j.mseb.2012.03.025

Tataroğlu A, Altındal Ş, 2009. The analysis of the series resistance and interface states of MIS Schottky diodes at high temperatures using I-V characteristics. Journal of Alloys and Compounds, 484(1-2), pp:405-409. doi: 10.1016/j.jallcom.2009.04.119

Turgut G, Aydogan S, Yilmaz M, Özmen A, Kacus H, 2021. An Investigation of Spray Deposited CdO Films and CdO/p-Si Heterojunction at Different Substrate Temperatures. JOM. doi: 10.1007/s11837-020-04514-9

Wang Q, Zhao Z, Li H, Zhuang J, Ma Z, Yang Y, Zhang L, Zhang Y, 2018. One-step RF magnetron sputtering method for preparing $\mathrm{Cu}(\mathrm{In}, \mathrm{Ga}) \mathrm{Se} 2$ solar cells. Journal of Materials Science: Materials in Electronics, 29(14), pp:11755-11762. doi: 10.1007/s10854-018-9274-y

Yeganeh MA, Rahmatollahpur S, Sadighi-Bonabi R, Mamedov R, 2010. Dependency of barrier height and ideality factor on identically produced small Au/p-Si Schottky barrier diodes. Physica B: Condensed Matter, 405(16), pp:3253-3258. doi: 10.1016/j.physb.2010.04.055

Yilmaz M, 2019. A function of external doping: Characteristics of inorganic nanostructure based diode. Ceramics International, 45(1), pp:665-673. doi: 10.1016/j.ceramint.2018.09.226

Yildırım M, 2019. Characterization of the framework of $\mathrm{Cu}$ doped TiO2 layers: An insight into optical, electrical and photodiode parameters. Journal of Alloys and Compounds, 773, pp:890-904. doi: 10.1016/j.jallcom.2018.09.276

Ylä-Mella J, Pongrácz E, 2016. Drivers and Constraints of Critical Materials Recycling: The Case of Indium. Resources, 5(4), p:34. doi: 10.3390/resources5040034 